THE TREATMENT OF FISH-CULTURAL WATERS FOR THE REMOVAL OF ALGÆ

From BULLETIN OF THE BUREAU OF FISHERIES, Volıme XXVIII, IgOS Proccedings of the Fourth International Fishery Congress : : Washington, I008

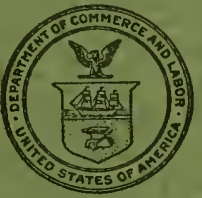

WASHINGTON : : : : : : GOVERNMLNT PRINTING OFFICE $::: \quad: \quad: \quad 1910$ 


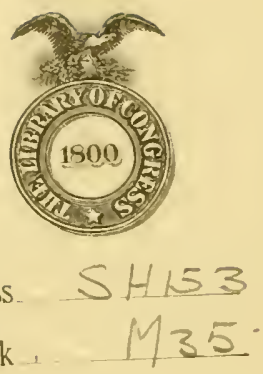






\section{THE TREATMENT OF FISH-CULTURAL WATERS FOR THE REMOVAL OF ALGÆ}

From BULLETIN OF THE BUREAU OF FISHERIIS, Volume XXVIII, I908 Proccedings of the Fourth International Fishery Congress : : W'ashington, Ipos

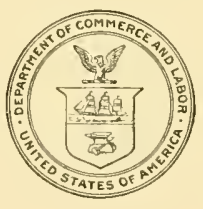

WASHINGTON $::: \quad: \quad:$ GOVERNMIENT PRINTING OFFICE $:: \quad: \quad: \quad:$ I910 
BUREAU OF FISHERIES DOCUMENT NO. 637

Issued April, 1910

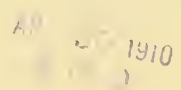




\title{
THE TREATMENT OF FISH-CULTURAL WATERS FOR THE
} REMOVAL OF ALGÆ

\author{
* \\ By M. C. Marsh and R. K. Robinson. \\ United States Bureau of Fisheries
}

Paper presented before the Fourth International Fishery Congress

held at Washington, U. S. A., September 22 to 26, 1908 


$$
-1
$$




\title{
THE TREATMENT OF FISH-CULTURAL WATERS FOR THE REMOVAL OF ALGÆ.
}

\author{
$*$ \\ By M. C. MARSH and R. K. ROBINSON, \\ United States Bureau of Fisheries.
}

\begin{abstract}
$*$
A great annoyance encountered at fish-cultural establishments, or in any ponds where fish are held, is the presence in the water of mossy or slimy plant growths consisting of forms known to botanists as different species of algæ. These appear usually as green or bluish green masses or strands of filaments, which clog the screens of ponds and supply canals and accumulate in the ponds themselves. The clogging of the intake screens or supply pipes endangers the life of the fish by reducing or entirely shutting off the water supply, while the clogging of the outlet screens prevents the water from escaping through the proper channel and allows the pond to fill and overflow, carrying away the young fish; in either case a loss of fish is likely to result, and the trouble of frequent cleaning of screens is inevitable. This sometimes requires the regular attention of the watchman all night or the special services of an extra laborer. The formation and accumulation of algæ within the pond containing fish, especially if there are fry or fingerlings, prevents proper feeding, greatly interferes with the operation of nets in landling fish, and occupies valuable space. The latter tends to crowding and retardation of growth, while frequently fry become entangled in the filaments and strands of the algæ in such a manner that many are lost from this cause alone.

It is true that the green filamentous algre which are mechanically so annoying are oxygenators in sunlight and often add materially to the amount of dissolved oxygen in the water. In ponds without a rapid circulation they have been observed to superaerate the water with oxygen, and this sometimes occurs in flowing streams; ${ }^{\prime}$ that is, the algæ add oxygen to water which already has absorbed its full or normal supply from the atmosphere. Under these conditions oxygen gas must have been passing slowly from the water into the atmosphere. The objectionable features of algæ, however, usually far outweigh the
\end{abstract}

a Marsh and Gorham: The gas disease in fishes, Report Bureau of Fisheries, 1904. P. 357. 1905. 
value as an oxygenator, or as a breeding place for minute animal food for fry, if such it be. A method of eliminating this growth is therefore a great desideratum in fish culture.

Moore and Kellerman, ${ }^{a}$ in work conducted with the object of cleansing municipal water supplies of obnoxious algx, developed a method of treating the water with copper sulphate, finding that this salt dissolved in the water is highly toxic to algæ at a dilution so weak that it may with safety be taken into the human system. The small cost of such treatment moreover, by reason of the cheapness of commercial copper sulphate and the simple means by which it may be used, makes this remedy readily available for practical purposes, and it has for several years now been successfully applied not cnly for the removal of algx from reservoirs and ponds, but also in the process of filtration as well. Its possibilities as a useful agent in fish culture have therefore invited investigation with, so far, the results set forth in this paper, concerning algæ as a mechanical annoyance to the fish culturist. Wider application is suggested in certain experiments dealing with bacterial diseases of fish, in which the treatment aims at physiological effect upon the fish themselves, but as yet no definite results in this phase can be reported.

\section{ESSENTIAL PRINCIPLES OF THE TREATMENT.}

The efficiency of copper sulphate in the treatment of city water supplies and fish-cultural ponds or streams depends, of course, fundamentally upon the fact that it is by its nature a poison to algæ. Its use for practical purposes depends further upon the fact that it is poisonous in extremely dilute solutions, which are not injurious to most of the higher forms of life and are moreover available by reason of the cheapness of the substance. The first point of consideration in fish culture, therefore, these facts being known, is the susceptibility of the fish contained in the water that is to be treated. If, under given water conditions, the fish are more susceptible than the algæ, the remedy is not applicable. U'se can be made of it only where as the proportion of copper sulphate increases the death point to algre is reached before the death point to the fish. The larger the margin the better, but the method may be used where the margin is very small. The second and remaining consideration is an adequate incthod of applying the remedy.

\section{SUSCEI'T1BILITY OF FISHES.}

The chemical reactions by which copper sulphate kills fish are not known. The poison acts through the medium of the water in which it is in solution and in which the fish breatles. The water las other dissolved substances in solu-

a A method of destroying or preventing the growth of algx and certain pathogenic bacteria in water supplies. Department of Agriculture, Bureau of Plant Industry, Bulletin No. 64, 1904. 
tion which tend to modify the effect of the copper salt, while the physiological resistance of the fish varies with individual fish and with different broods of the same species. As a matter of fact, fish in general resist the action of copper sulphate better than algæ. The salmonoid fishes have less resistance than any group with which experiments have been made; nevertheless, it has been found in most cases thus far that the necessary margin between the death point of fish and the death point of algæ does exist. Algx, including some species that cause annoyance, are sometimes killed by much weaker solutions than the weakest known to be fatal to the most susceptible fish, even as weak as I part copper sulphate to $50,000,000$ parts of water.

The variation of the two important facts, however, susceptibility in individual broods of fish and in the dissolved content of the water, giving rise to wide differences in the quantity of copper sulphate that may be fatal, makes it necessary to determine in each case the susceptibility of the fishes in question in the particular water concerned. It follows that no general formulæ for the proportion of copper sulphate can be stated. Some results actually obtained will be of interest, however, and useful for comparison or to some extent in approximating the strength of the solution which must be fixed more accurately by experiment.

Moore and Kellerman give the following as the number of parts of water to one part of copper sulphate in dilutions which will not injure fish of certain species: ${ }^{a}$
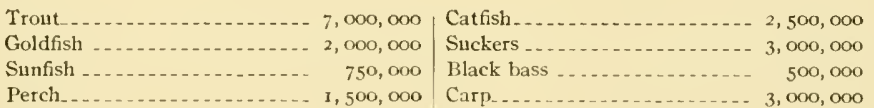

These dilutions are presumably close to the death points in the particular water used and with the particular fish experimented with. ${ }^{b}$ The trials on which the figures for trout (Salvelinus fontinalis) are based show the greatest susceptibility to copper sulphate yet observed for fish. They were made at Cold Spring Harbor, N. Y., and fatal results were obtained at I to 6,500,000 with fingerling trout during 2 -hour exposures. At Bayfield, Wis., however, adult trout resisted 1 to 500,000 during this period. These are probably extreme cases. In the former algæ probably could not be killed in the presence of the trout, and it is the only case of its kind that has come to the attention of the writers.

$a$ Copper as an algicide and disinfectant in water supplies. Department of Agriculture, Bureau of Plant Industry, Bulletin No. $7^{6}$, p. 11, 1905.

$b$ It is of interest to note in this connection that, according to $M 1 r$. Kellerman, copper-killed fish are of little use for table purposes on account of the rapidity of decomposition, which seems to proceed more rapidly than with those killed in the ordinary ways. Moreover, the dead fish have usually an unattractive appearance, due to the distention of gills and jaws. 
Some laboratory experiments were made at the Bureau of Fisheries with brook trout fry and yellow perch. The trout fry were held in shallow dishes with about one liter of water. The dishes were floated on the surface of cold water to maintain a proper temperature, which was $52^{\circ} \mathrm{I}$. or under during the trials. The dilution in the dish was aerated only by contact with the air. In every dilution tested 10 fry were used in each trial; : to 500,000 was fatal to most of these fry within $2+$ hours; 1 to $1,000,000$ killed no fry during $+S$ hours. Intermediate dilutions killed a portion of the sample of 10 during $t^{8}$ hours. Potomac water was used, having at this time an alkalinity of about 53 parts per million.

Aclult yellow perch (Perca flavescens) were tried in so liter samples of the dilution made with Potomac water held in tall glass jars with only air surface aeration. One perch only was used in each trial. A dilution of I to 1,000,000 killed the fish within $24-40$ hours; I to $2,000,000$ was fatal after $48-64$ hours in one case, while in another the same dilution was safe during 5 days; i to $2,500,000$ was fatal after 68 hours; I to $3,000,000$ was safe during 7 days.

Fingerling large-mouth black bass (Micropterus salmoides) proved much more resistant than adult perch. Under the same general conditions as those above described for perch a dilution of I to ro0,000 killed the fish within 24 hours, while I to 200,000 , as well as several weaker dilutions, did no harm during 5 days.

Moore and Kellerman in laboratory experiments found that the eggs and fry of large-mouth black bass and very young crappie fry were not injured by I to $1,000,000$. Carp were found usually to succumb to i to 500,000 .

Sunfisl (Eupomotis gibbosus) in a turbid Potomac water dilution were not killed by 1 to 400,000 during 21 hours. Mummiclogs (Fundulus heteroclitus) were killed by 1 to 750,000 , but not by 1 to $1,000,000$. The temperature of the dilution in these cases was $78^{\circ}-80^{\circ} \mathrm{F}$.

Silver nitrate has also a very high toxicity both to algæ and to fish. It is probably its expense alone that prohibits its usefulness for some of the same purposes for which copper sulphate is used. Chinook salmon fry about three months old are killed within 48 hours by a solution of 1 part of silver nitrate to $22 \frac{1}{2}$ million parts of water, while I part to 25 million parts of water is on the border line of safety, and killed a portion only of the several fry used in the test. No substance more poisonous to fishes is known to the writers.

\section{METHOD OF ADMINISTERING THE TREATMENT,}

In the treatment of fish-cultural waters with copper sulphate there are, of conrse, from the mechanical standpoint, two kinds of water to be dealt with, namely, still water and flowing water. I'or still water the process is comparatively simple, only a single "dose" being required. Such treatment is, however, applicable only where renewal of the water may be dispensed with for the period 
during which the remedy is to act. With flowing water the case is more complicated, owing to the necessity of providing a continuing and uniform inflow of the copper sulplate solution adjusted to or varying with the water flow. To do this a convenient method is to dissolve the sulphate in water and allow the solution to flow into the water that is to be treated. The requisites to this operation require some special discussion.

The strength of the admixture (otherwise termed the dilution) in the pond or stream will depend upon four factors-(I) volume of the water flow that is to be treated; (2) volume of the solution of copper sulphate that is to flow into
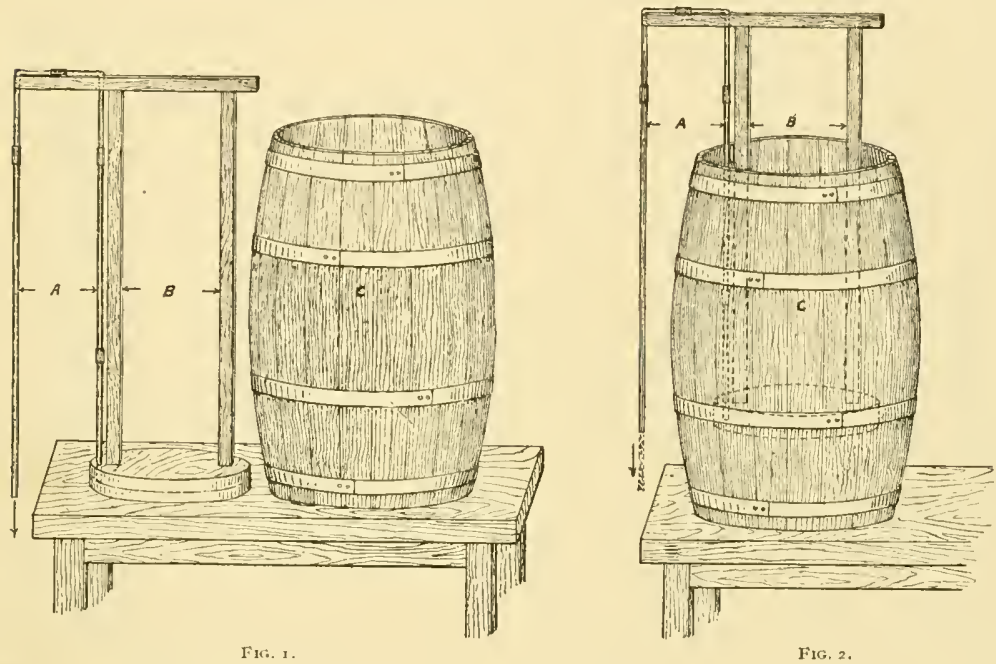

NoTE.-In each figure $A$ is the siphon, $B$ the frame, and $C$ the container. The form of the frame is of course not essential, and should be adapted to the container. The illustrations show the glass tubing of much larger size than is necessary or practicable in small siphons. Small tubing is preferable.

it; (3) rate of flow of the solution; and (4) quantity of salt dissolved in the solution. The first factor is fixed and must be ascertained. The otler three may be varied as convenient to produce the desired strength of admixture. Any two of these three being fixed, the desired result may be obtained by varying the other one. The delivery of the solution at an unvarying rate into the water flow is perhaps the greatest difficulty and is not to be accomplished by any of the ordinary means of delivering liquids from containers.

If a pipe or tube taps a reservoir containing the solution the head is constantly changing as the level of the solution in the reservoir is lowered. The flow 
of solution therefore gradually slows and the concentration in the water treated is constantly falling. If a fixed siphon is used the same difficulty is met. The rate of flow through the siphon depends on the head of the solution, and is therefore never constant. The simplest way to meet this difficulty is the use of a floating siphon, and this is an essential part of the method herein described. A siphon made of glass tubing with rubber connections may be mounted upon a wooden frame and the frame built upon a substantial float. The simplest carpentry suffices to adapt it to almost any shape or size of container. (See lig. 1.) The frame holds the siphon in such fashion that one arm hangs outside the container and the other in the solution. The outer arm is made the longer, giving sucl head as is desired. The inner arm passes through the float, ending flush with its lower surface. The frame carrying the siphon floats on the surface of the solution, falling as the level of the latter is lowered. (Fig. 2.) The siphon always has the same relation to this level, and therefore the head is always the same and the flow constant. It is better that the frame be light in weight, relative to the base or float, so that it will float nearly upright, or else guides must be placed at the top of the container to hold the frame in position. This flow of solution may be delivered to the water flow directly or led to it by troughs or any convenient way.

\section{DETAILS OF THE CONTINUOUS TREATMENT.}

The metric system is of such great convenience for the measurements and calculations involved that it is used throughout this description, a table for conversion to other units being given. It is worth while to calculate by the metric system, and, if measurements have to be made by other systems, to reduce them to metric units. The reason for this lies both in the advantage of decimal calculation and in the simple relationship of the metric units for weight and volume. Ifor practical purposes 1 cubic centimeter (c. c.) of water weighs I gram, and I liter (1,000 c. c.) of water I kilogram, 1,000 grams, or 1,000,000 milligrams (mg.). Small metric graduates and rules are easily obtained. Weighing will more commonly be by avoirdupois, and conversion should be made. Some method of measuring small volumes should be available. A t cubic centimeter volumetric pipette graduated in fifths or tenths is very useful. ${ }^{a}$

For the actual use of fish culturists or others, the details of methods, procedure, and apparatus necessary to apply copper sulphate continuously to waters containing fish for the elimination of algæ or for other purposes, without injury to the fish, are as follows:

a Such pipettes, marked in tenths of a cubic centimeter, may be obtained for about 25 cents each from İimer \& Amend, 205 Third avenue, New Vork City; Arthur H. Thomas \& Co., Twelfth and Walnut streets, Philadclphia; or Bausch \& Lomb Optical Company, Rochester, N. Y. 
I. DETERMINATION OF PROPORTION OF COPPER SULPHATE.

It is first necessary to ascertain with a reasonable accuracy the amount of copper sulphate required to kill the fish which are in the water that is to be treated. Every species concerned should be tested. For this determination it will be sufficient at the beginning to make the test for 24 -hour periods in standing water, with controls (i. e., extra or duplicate cans, of the same capacity, containing the same quantity of water and the same number of fish, the only difference between the two being that ore holds copper sulphate dissolved in the water and the other does not). Fish cans may in most cases be used as containers for the dilution in which the fish are placed and for the control. Any receptacle large enough to hold a few individuals of the fish to be tested will answer for this. A stock solution, from which to prepare the above dilutions, should be made up in a glass bottle.

The stock solution may be made holding 10 grams of copper sulphate per liter of solution or, in other terms, approximately one-third of an avoirdupois ounce, or $1+6$ grains, of copper sulphate, with enough water added to make I quart of solution, is a sufficient equivalent. Each cubic centimeter of this solution will then contain Io mg. of copper sulphate. If the test is to be made with trout a test dilution of 1 to $1,000,000$ may be made; that is, to 10 gallons $(37,854$ c. c., or $37,854,000 \mathrm{mg}$. $)$ of water should be added $37,854,000 \div 1,000,000=37.8 \mathrm{mg}$. of copper sulphate, or $37.8 \div \mathrm{IO}=3.78 \mathrm{c}$. c. of the stock solution. (The error in omitting to first remove $3.7 \mathrm{c}$. c. of water from the ro gallons is negligible.) This test dilution should be thoroughly stirred. A few fishes should be introduced, not more than the water will readily support for 24 hours or more without artificial aeration, as shown by the control. The function of this extra or duplicate can or container, that of checking the result, is obvious. After a certain amount of experience it may be omitted.

If the fishes all die in the test dilution while those in the control are alive, a new trial should be made, using a weaker dilution. If they are all alive at the end of 24 hours, a new trial should be made, using a stronger dilution. When some of them live and some die during the 24 hours, the death point will have been nearly fixed. The trials should be continued until it is ascertained what is the strongest dilution of sulphate that may be used and yet leave all the fish alive at the end of $2+$ hours.

Having thus determined approximately the maximum amount of copper sulphate that can be safely used, the treatment may be begun with somewhat less than this amount. It is now necessary to determine the volume of water flow which it is desired to treat. 


\section{MEASUREMENT OF THE WATER FLOW.}

If the flow is small and so delivered that the volume flowing during a few seconds or half a minute may be caught in containers, it may be measured directly. If the flow is too large for this or is through ground pipes, conduits, or ditches in one plane, other means must be resorted to. Technical methods, by the use of current meters, the pitometer, or weir measurements may be used where available. It is intended to discuss here only the simple methods open to anyone without the use of technical instruments.

Where the water is delivered into a pond of reasonably regular shape, it is often easy partly to draw off the water, measure the space thus drawn off, and calculate its cubic contents. The pond may then be allowed to fill up to the original mark and the time required noted. A fair estimate of the flow per minute may thus be readily obtained. If the delivery is below the surface of the water in the full pond a slight error is introduced by the change of head, whicl is decreasing as the water rises. This error may be minimized by lowering the pond only a few inches, or the least distance that will permit an estimate to be made. Often this estimate may be checked by the following method:

When the flow passes through a completely filled closed conduit the cubic contents of which may be measured, it is sometimes feasible to determine the speed of the flow through this conduit. 'This may be done by observing the time required for an object to be carried entirely through the conduit by the current, the instant of its entering and leaving this current at each end of the pipe being accurately noted. A block or ball of wood floating through the upper portion of the conduit is not a good instrument for determining the speed of the flow, being apt to scrape the inner surface of the conduit and be retarded; besides, the current is slowest next the surface and fastest in the center. A round, short-neck bottle may be weighted with shot and tightly corked, so that its specific gravity is almost exactly the same as that of water, and when completely submerged it will neither rise nor sink. It will thus remain (in shallow water) at about whatever depth it is placed, for a considerable time at least. If the bottle is of such length that it approaches the diameter of the conduit, say three-fourtlis of the diameter, it will, after starting properly, float submerged three-fourths of the cross section of the pipe, be thus acted upon by the currents of different rate and give a fair basis for the average speed of the water in the conduit. From this speed and the cubic contents of the conduit the volume delivered per minute is easily calculated.

Flow in open flumes or ditches can easily be measured. Simple modifications of the above method, which it is unnecessary to detail, will readily suggest themselves. 
In a case where the writers applied both methods of estimating flow, the lowering and refilling a pond and measurement of speed in a closed pipe, I, I 27 gallons per minute were obtained as the result by each method. The exact agreement was a mere coincidence, since these methods can not be presumed to have the degree of accuracy implied, but it indicates that flow may be estimated in a practical way by these means.

The more accurately the flow is known the more rapidly and confidently may the treatment proceed. But it is not necessary to refrain from the treatment even if no measurement of flow is possible. Any person practiced in estimating water flow with some accuracy by the eye may make a minimum estimate. Using this as a basis, a dilution of copper sulplate, much weaker than the susceptibility experiments indicate, may be assumed as safe. The treatment should then be cautiously begun with constant watching of the trout and testing them with food. As a fatal strcngth of copper is approached they will be thrown "off their feed." While they remain unaffected the strength may be gradually increased until the desired effect is obtained.

\section{DETERMINATION OF VOLUME, STRENGTH, AND RATE OF INFLOWING SOLUTION.}

The desired dilution and the volume of water flow per minute are now known. The volume of copper sulphate solution, the weight of copper sulphate crystals which are to be dissolved to make this solution, and the volume of flow per minute from the siphon to produce the desired dilution, are to be determined. These three may be mutually arranged in the way which is most convenient. Since it is less easy to change the siphon flow, or to make a siphon which will have exactly a given and predeternined flow, it is better to adjust the volume of solution and weight of sulphate to the fixed siphon flow whatever it is found to be after setting up and starting. The siphon may be made to deliver small amounts, even drop by drop, if desired. A flow of $20 \mathrm{c}$. c. to $100 \mathrm{c}$. c. or more per minute covers most cases. The flow should not be so large that renewal of the solution is too often required. If the siphon flow first hit upon is not within reasonable limits it may be increased by lengthening the outer arm or by increasing the diameter of the orifice in the siphon nozzle. It may be decreased by shortening the outer arm.

Having now the siphon flow determined, as well as the dilution and the water flow, the volume of the sulphate solution and the weight of sulphate to be dissolved for one filling of the container of the solution remain to be fixed. It will be natural to approximately fill the container. The volume is thus fixed and the weight of sulphate must be adjusted with reference to it. On the other hand, if only a given weight of sulphate is available, too small an amount to make 
the desired solution fill the container, the volume of the solution may be adjusted with reference to this weight of sulphate, instead of vice versa.

The relationships of the five factors may now be given in the shape of formularies. To use these it is better to reduce the water flow per minute to milligrams, though the figures may seem unwieldy. This is done by reducing it to liters and multiplying by $\mathrm{r}, 000,000$.

The proportion (by weight) of the copper sulphate to the water is here designated for brevity and convenience as the "dilution;" c. g., a dilution of I to I, 000,000 , or I : $1,000,000$. In formulx and in computing, the figure expressing the copper sulphate is omitted, as, "dilution" =1,000,000.

If $a$ is the dilution, and $b$ the water flow in milligrams per minute, then $\frac{b}{a}=$ milligrams of copper sulphate necessary to flow through the siphon every minute.

If $c$ is the siphon flow in c. c. per minute, then $\frac{b}{a \times c}=$ milligrams of copper sulphate which each c. c. of solution must contain.

If $z=$ the number of milligrams of copper sulphate to be dissolved, and $y=$ the number of c. c. of copper sulphate solution to be in the container at the beginning; then

If $z$ milligrains of copper sulphate are to be dissolved, $\frac{z \times a \times c}{b}=$ number of c. c. of solution to be made.

Or, if $y$ c. c. of solution are to be made, then $\frac{b \times y^{\prime}}{a \times c}=$ number of milligrams of copper sulphate to be dissolved.

These expressions are put in words as follows:

Divide the milligrams of 'water flow per minute by the dilution; the result is the milligrams of copper sulphate necessary to flow through the siphon every minute.

Divide the milligrams of water flow per minute by the product of the dilution multiplied by the siphon flow in c. c. per minute; the result is the number of milligrams of copper sulphate which each c. c. of solution must contain.

Multiply together the dilution, the siphon flow in c. c. per minute, and the number of milligrams of copper sulphate to be dissolved; divide the product by the number of milligrams of water flow per minute; the result is the number of c. c. of solution to be made. But, if the latter has already been decided upon, and the number of milligrams of copper sulphate to be dissolved is unknown, then:

Multiply the number of milligrams of water flow by the number of c. c. of solution to be used; also multiply the dilution by the siplion flow in c. c. per minute; divide the former product by the latter product; the result is the number of milligrams of copper sulphate to be dissolved. 
The solution should be made by dissolving the necessary weight of sulphate in a relatively swall amount of water and then "making it up" to the necessary volume by the addition of more water. If this volume of water is taken at the beginning the solution will be too large, since the sulphate crystals add to its volume. In some cases the error involved is negligible.

\section{SINGLE-DOSE TREATMENT.}

In the application of copper sulphate to large ponds which have a rather small water flow and in which the circulation is therefore sluggish and the same water remains in the pond for a considerable period, the treatment by a continuous flow of solution is not so effective as that by "single dose." The reason is that all waters that support fishes are slightly alkaline, and this alkalinity slowly precipitates the copper from solution. The writers have tried the siphon treatment twice in bass ponds with very little effect, although a much stronger dilution was used than was effective in trout ponds having a much more rapid circulation. In the case of these bass ponds the effect on the algæ was shown only about the intake to the ponds, and did not extend more than 25 or 30 feet from the point where the water entered. The reason for this restriction of the toxic action is taken to lie almost entirely in the prolongation of the time factor. To be effective the sulphate after it is dissolved must come quickly in contact with the algæ. The water moves very slowly through these ponds, and during this time the copper is being constantly precipitated from solution. In the precipitated form it does not impregnate the water uniformly, as in the case of a solution, but is gathered in minute particles which moreover do not have the intimate contact with the algal filaments which is necessary in order to exert a toxic action.

In large sluggish ponds, therefore, it is better to treat them with one dose of copper sulphate, the dilution being calculated to the whole volume of water in the pond. In other words, a given amount of sulphate is added at one time, as if the pond were a body of standing water without a current flowing through it. There is no continuous addition of the sulphate. In applying this treatment the flow may be actually cut off during the process if the fishes will endure this temporary loss of water supply; or an allowance may be made for the water entering during this period; or the inflow may be ignored if the pond is large. With a knowledge of the actual conditions, a choice may be made among these alternatives. In pond culture a constant flow of water to a pond is unusual except for supplying small-mouth black bass. The other species reared by pond culture, ${ }^{a}$ chiefly large-mouth black bass, sunfish, and crappie, do not require a constant flow and it is customary merely to supply 
sufficient water to compensate for craporation, scepage, etc. If the bottom of the pond has considerable springs of water the volume delivered nay be taken into account as far as it is possible to do so in calculating for the dilution, unless it is small enougl to be ignored.

The first step is to determine the susceptibility of whatever fishes are held in the water to be treated. This will be done in quite the same way as already described under the siphon treatment. I'ond-culture fislies will for the most part endure more copper sulphate than trout. The total volume of water in the pond must then be ascertained. The dilution to be used will be indicated by the susceptibility, allowing an ample factor of safety. The inilligrams of water in the pond divided by the dilution will give the milligrams of copper sulphate to be used. This will be readily reduced to pounds or ounces or other unit and the anount weighed out. It may be placed in a bag of cheese cloth, burlap, or of other loose-meshed material, and dissolved in the pond by dragging it about at the surface from the stern of a boat. ${ }^{a}$ The more thoroughly all parts of the pond are traversed the more uniform the distribution of the sulpliate.

If the algal growth is very abundant only part of it may be killed by the first treatment. When there are large masses of algæ all the copper may be used up before the whole of the mass is destroyed. After algx have grown unchecked in ponds for a long time the growth may mat heavily together, or where there is a current it may form long strings or ropes. These more densely nassed bodies of algal growths are less susceptible to treatment. The outside strands may be killed while the inner portions remain alive, being protected by the outer. In such cases as these tlie dose may be repeated after an interval of time, as a few days or a week. If the pond can once be made free of algx, it is much easier to keep it so than to kill off heavy growths. It is not always possible, however, to eliminate all growths while fish remain present. The species of algx vary considerably in their susceptibility to copper, and some may therefore survive on account of their natural resistance to the strongest dilution the susceptibility of the fishes concerned permits to be used.

\section{MISCELLANEOUS DIRECTIONS AND CAUTIONS.}

To make the siphon which is to be attached to the float, glass tubing with rubber connections should be used. The smaller sizes of tubing are preferable, that with an outside dianeter of 4 to 6 millineters, or five-thirty-seconds to one-fourth inches, being convenient. The tubing sliould be bent approximately at riglit angles to make the turns at the top of the float, the bending being done best by licating in the yellow flame of an ordinary gas jet. The tubing should 
be held to coincide flatwise with the upper edge of the flame, meanwhile turning slowly on its own axis, until it softens. The flame of a large kerosene lamp or of an alcohol lamp will answer, but will not make as good a bend.

Glass tubing may be neatly broken without cracking by slightly scarring its circumference with a file at the desired point and then, by grasping the tubing firmly with both hands, one on each side of the scar, pulling strongly in a longitudinal direction, making simultaneously a slight stress at right angles. A clean break will occur exactly at the scar.

Nozzles, which are convenient as ends to the outer arm of the siphon, may be made by drawing out in the flame several short pieces of glass tubing and breaking off at some point along the constriction. They may be attached by means of the usual rubber-tube connection. They are not necessary to deliver the flow, and the outer arm may end merely by breaking off slarp; but they give this advantage, that the length of the outer arm, or the size of its orifice, or both, may be quickly changed with their aid, and thus the siphon flow may be quickly and easily varied. For convenience a number of these nozzles may be made, differing sufficiently in length or orifice to give different flows and marked or labeled accordingly. By inserting a given nozzle a given flow may be quickly obtained or a change quickly made. In making these changes care must be taken not to change the length of the siphon arm above the point of attachment of the nozzle if the labeled flow is desired.

It is of course absolutely necessary that there be an intimate mixture between the solution flowing from the siphon and the water flow which is being treated; otherwise a uniform dilution will not obtain. The sulphate will be too strong in places and too weak in others, which may cause the loss of fish and fail to kill the algx or accomplish the purpose desired. For this reason it is well to deliver the siphon flow at the beginning of the conduit, so that mixing may occur as the water flows. The agitation and mixing at the bulkheads of ponds usually makes a uniform distribution of the sulphate. It will not do to deliver the sulphate at a point where the water inflow to a pond enters quietly with little fall, causing no mixing swirl. It may sometimes be necessary to provide special means for stirring to obtain a mixture.

The stock solution of copper sulphate should not be kept in containers made of ordinary metals. No metals should be allowed in any way to come into contact with the solution. If the flow of sulphate solution to the water has to be conveyed by troughs they should be of wood. Galvanized iron or tin is soon eaten through, and usually can not by painting be sufficiently protected from the action of the copper sulphate. Weak dilutions, however, such as those used for testing susceptibility of trout, may be used in fish cans. The sulphate is not strong enough to attack the metal notably. 
It is necessary to avoid leakage from any containers holding the sulution in the vicinity of ponds containing fish, since the leak may easily find its way into the ponds.

Special care should be taken in all the calculations and they should be reviewed before the treatment is begun in order to correct mistakes and to see that all factors have been taken into account. The measuring of the water volumes in fish cans and in the solution container, and the weighing of the sulphate for this solution, need but ordinary accuracy. The volume of the stock solution and the weight of the sulphate to be contained in it, however, should be determined with special care and accuracy, since the quantities concerned are small and the error is of greater importance. The scales or balances used should weigh to fractions of ounces.

The difficulty of weighing fractions of ounces in making the stock solution where delicate scales or balances are not available may be obviated by making several times the volume stated, thus using a greater weight of sulphate; or by making the stock solution several times too strong and then properly diluting it. In much the same way portions of the stock solution may be measured in the absence of measures of small volumes. The least conveniently measurable portion should be taken, diluted accurately, the proper portion of the dilution used, and the rest thrown away.

The cost of commercial copper sulphate is about ro cents per pound in small quantities and about 8 cents in large quantities. It is in the form of crystals, which contain five molecules of water of crystallization. This fact is expressed by the chemical formula $\mathrm{CuSO}_{4}+5 \mathrm{H}_{2} \mathrm{O}$. The weight of these crystals is therefore made up of about 36 per cent water. No account is taken in this paper of this water of crystallization. All references to copper sulphate, or to the strengths of solutions of copper sulphate, or to the dilution, are based upon the crystallized commercial substance consisting in part of water. The actual amount of the anhydrous chemical compound, copper sulphate, actually contained in the solution, in the dilution, etc., is about 64 per cent of the amounts stated. This fact interferes in no way with the calculations used for the treatment herein proposed. In quantitative chemical calculations, however, it is necessary to take account of the water of crystallization.

Clean rain water, or distilled water, is better for making the stock solution than spring or creek water.

The sulphate is best dissolved by suspending it in a burlap or loose-meshed bag near the surface of the water in the container. It then dissolves rapidly and without attention, the heavier solution tending to sink. Stir thoroughly after all crystals are dissolved. If the crystals are at the bottom of the container they dissolve very slowly unless constantly stirred. 
The first effect to be seen upon the algæ when the concentration reaches the toxic point is a slight fading of the natural color. When killed the algæ filaments become gray and shrivel markedly, occupying much less space than while alive. The effectiveness of treatment is increased in warmer water.

While trout are considered the most susceptible of the species used in fish culture, there are probably some exceptions, at least under some conditions, as not all species have been tested. Several white suckers at White Sulphur Springs in one instance succumbed to a treatment which did not injure trout in the same waters. Care must be always exercised in the matter of susceptibility.

Great care should be exercised in the manipulation of the copper sulphate salt, the copper sulpliate solution, and in the calculations. The substance is not a very deadly poison, yet it may have unpleasant effects upon the human system. Ordinary handling of the salt or the solution will result in no trouble. The siphon should not be started by mouth suction directly on the siphon arm, however. A moderately strong solution taken into the mouth results in a very disagreeable irritation of the mucous membrane and sometimes nausea. Attach a small rubber tube to the siphon nozzle and fill the whole siphon tube by suction; then pinch rubber tube to prevent back flow and detach it; the flow will start.

\section{ILLUSTRATIVE AND SUGGESTED APPLICATIONS OF THE TREATMENT.}

AT BAYFIELD, WIS.

The first experiment in the treating of water by this method on a considerable scale was made at the Bayfield station of the board of fish commissioners of the State of Wisconsin. A flow of 1,127 gallons of water per minute was treated continuously for 47 days with copper sulphate so that a dilution was maintained varying from $I: 1,250,000$ to $I$. I,700,000. The dilution was varied at will from time to time for various reasons. Upward of 15,000 brook, brown, and rainbow trout from 2 to 3 years of age were held in this water, and during the treatment no injury was done to any of them. The immediate result of the treatment was the cessation of trouble with algæ in the ponds affected by the flow, a trouble consisting cliefly in the necessity of frequent cleaning of the screens at the outlets of the ponds. The treatment ceased on July 1. Thereafter during the summer the algæ sprang up again, and much attention was necessary to the screens to keep them free of the clogging strands of the filamentous species common in these waters.

This effect upon the algæ was not the purpose sought in this experiment at the Wisconsin station, but was incidental thereto. For several weeks of each summer the brook and other trout at this station are attacked by bacterial infection, the specific cause of which has been described under the name Bacterium truttce. The ravages of this parasite are worst while the temperature ranges 
between $50^{\circ}$ and $60^{\circ} \mathrm{F}$. Copper sulphate even in weak dilution inhibits its action. It was therefore thought that by impregnating the water continuously with this salt, at a dilution harmless to the trout, during the few weeks while the disease usually prevailed, the loss caused by it could be prevented. On account of a break in a conduit and the loss of a large number of the experimental fish from certain ponds, the results of this trial were inconclusive. The total losses in the ponds affected, as compared with those in control ponds, so far as they are of any significance indicate a considerable inhibition of the disease among the brown trout, but the demonstration is not suffcient to set up a claim of practical prevention of the disease in question. The value of this application is for the future to determine. But the particular experiment cited is held to demonstrate the feasibility of long-continued treatment of large volumes of flowing water containing trout with dilutions of copper sulphate of sufficient strength to have an inhibitive effect upon bacterial parasites of fishes and to be at the same time harmless to trout. The expense moreover is well within the means of fish cultural operations. In the case cited it was less than \$I per day. The volume of water treated was unusually large, being more than 1,000 gallons per minute.

AT WHITE SULPHUR SPRINGS, W. VA.

At the United States fisheries station at White Sulphur Springs, W. Va., copper sulphate was applied to the water supply of ponds containing trout for the specific purpose of eliminating troublesome algæ. A floating siphon apparatus was used, similar to that already described, but on a much smaller scale. By 24-hour trials of a few fry in fish cans with copper-sulphate solutions of different strength, the approximate strength which the species would endure for this period and in the given water was ascertained to be about 1 part of sulphate to $3,000,000$ of water. The flow of water was estimated at 1,000 gallons per minute. The siphon flow was adjusted so that the above strength was applied to the whole flow. Within $2+$ hours a marked effect upon the algæ was visible, and a few trout in the raceway which conveyed the water to the ponds were killed. None of the trout (both fingerling and adult brook and rainbow) in the ponds were killed, but the sulphate was not without its effect upon them. It was noticed that the fry either did not feed with their accustomed readiness or refused food altogether. Like cattle and other domestic animals, they were "off their feed." On this account the strength of the solution was readjusted so that a $I$ to $4,000,000$ flow was maintained in the ponds. In the case of this dilution there was still a noticeable effect upon the trout, as evidenced by their refusal to take food. With young fish-fry and fingerlings-this effect was seen after about $\delta$ hours' application of the treatment. With adult 
trout it was not noticeable under 20 hours, but after this period they also refused food. If the treatment was discontinued at the end of 24 lours, both fry and adtults would resume feeding with their accustomed vigor within the next 24 hours.

The use of the I to $4,000,000$ dilution, repeated about once a week for a duration of 8 hours each time, proved sufficient to keep down the algal growths without harm to the fish. The cost of the copper sulphate used in this treatment was at the rate of about 30 cents per 24 hours.

In the summer of 1907 a pond of an area of 0.68 acre and with an average depth of 18 inches, containing 28 adult large-mouthed black bass and several thousand advanced fry, was treated with 4 pounds of copper sulphate in single dose. The treatment was entirely effective in destroying the algæ and, as far as could be seen, without the loss of a fry or an adult.

\section{AT FISH LAKES, WASHINGTON, D. C.}

As a part of some joint experiments conducted by the Bureau of Plant Industry and the Bureatl of Fisheries two small ponds, each containing a few adult bass ready to spawn, were treated on April 22 with copper sulphate in a dilution of 1 to $5,000,000$. The water subsequently became roily, so that observations could not be made on the nesting and spawning bass, but on May 8 a fine brood of bass fry was observed. With the disintegration of the algæ myriads of Daphnia appeared. On June 12 a pond of 1.55 acres, with an average depth of $203 / 4$ inches, was treated with 1 to $5,000,000$. This pond contained adults, fry, and baby fingerlings of the large-mouth black bass. Careful observations about the pond and of the young fish seined from it daily after the copper was administered showed no harmful effects upon the fish. By June 22 much of the algx had disappeared, comparatively little remaining. Its disintegration caused the water to impart a very offensive odor when stirred.

This dilution was far weaker than any which, as far as experiments indicate, could in the least harm the species of fish concerned, but it was nevertheless strong enough to eradicate the particular growths of algæ then existing in the ponds.

\section{FURTHER POSSIBILITIES OF THE TREATMENT.}

The success of the copper-sulphate method of treating fish-cultural waters for the removal of a mechanical nuisance indicates successful fish-cultural application of the remedy in other directions. The administration of remedies for disease in the lower animals is familiar in the case of the farmer's live stock and other domestic land animals, being the science of veterinary medicine. Upon fishes, however, medical treatment has been practiced but inconsiderably, 
notwithstanding the fact that they, too, have been brought under domestication and are subject to all the increased susceptibility to disease that is always consequent upon this more restricted life. The difference is due in part to the relative youth of the science of fish culture and the, so far, relative absence of disease, and in part to the difficulty of administering medicine in the presence of water, from which the fishes can not long be separated. It is obvious, however, that with a remedy that may be applied externally and a process for applying it by means of the water the fish live in, important possibilities are at hand. If copper sulphate, for instance, can be shown to be toxic to the pathogenic bacteria and external parasites of fishes in dilutions yet harmless to the fishes themselves, it will have a much wider usefulness in fish culture than its present application. The only experiments to this end so far undertaken have been inconclusive, but future experiments may be expected to show useful results in this field.

TABLE OF METRIC EQUIVALENTS.

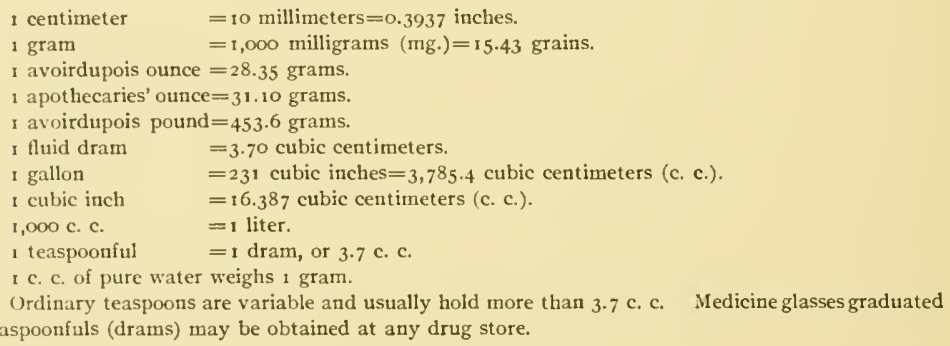






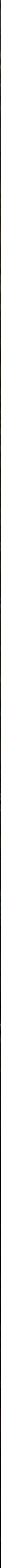

